\title{
Pedagojik Formasyon Öğrencilerinde Umut ve Mental İyi Oluş: Yapılandırmacı Düşünmenin Aracı Rolü*
}

\author{
Hope and Mental Well-Being in Pedagogy Formation \\ Students: The Mediating Role of Constructive Thinking
}

\author{
Ayşe Sibel DEMIRTAŞ**, Kemal BAYTEMİ***, Ali GÜLLÜ****
}

\begin{abstract}
Öz: Bu çalışmada, pedagojik formasyon öğrencilerinde umut ve mental iyi oluş arasındaki ilişkide yapılandırmacı düşünmenin aracı rolü test edilmiştir. Araştırmanın çalışma grubu, Alanya Alaaddin Keykubat Üniversitesi'nde pedagojik formasyon eğitimine devam eden, 212'si kadın (\% 74.4), 73'ü (\% 25.6) erkek toplam 285 kişiden oluşmaktadır. Araştırmaya katılanların yaş ortalamaları 20.49, $\mathrm{Ss}=$ 2.09'dur. Verilerin toplanmasında Sürekli Umut Ölçeği, Warwick Edinburgh Mental İyi Oluş Ölçeği ve Yapılandırmacı Düşünme Envanteri kullanılmıştır. Araştırmada, betimsel istatistikler, Pearson korelasyon katsayısı ve aracılık analizleri kullanılmıştır. Elde edilen bulgular, umut, yapılandırmacı düşünme ve mental iyi oluş arasında pozitif yönde anlamlı ilişkiler olduğunu ortaya koymuştur. Aracılık etkisi için yapılan analizde ise umut ile mental iyi oluş arasındaki ilişkide yapılandırmacı düşünmenin kısmi aracı rolü istatistiksel açıdan anlamlı bulunmuştur. Araştırmanın sonuçları alanyazın ışığında tartışılarak, ruh sağlı̆̆ı alanında çalışan uzmanlara ve araştırmacılaraönerilerde bulunulmuştur.

Anahtar Kelimeler: Umut, mental iyi oluş, yapılandırmacı düşünme, aracılık
\end{abstract}

\begin{abstract}
The main aim of the current study was to examine the mediating role of constructive thinking in the relationship between hope and mental well-being on studentsof pedagogy formation program at Alanya Alaaddin Keykubat University. The study group comprised of 212 female (\% 74.4) and 73 male (\%25.6). The study was carried out with 285 students, the mean age was $20.49(\mathrm{Sd}=2.09)$. Dispositional Hope Scale, Warwick Edinburgh Mental Well-Being Scale and Constructive Thinking Inventory were applied in data collection. Descriptive statistics, Pearson correlation coefficient and mediation analysis were used in analysis of data. According to the findings, there were significant positive correlations between hope, constructive thinking and mental well-being. The mediation analysis showed that constructive thinking had apartial mediation effect in the relationship between hope and mental wellbeing. Research findings were discussed in the light of the literature and some suggestions were proposed for mental health experts and researchers.
\end{abstract}

Keywords: Hope, mental well-being, constructive thinking, mediating

\section{Giriş}

Pozitif psikoloji, pozitif duyguların ve pozitif karakter özelliklerinin gelişimiyle ilgili araştırmalar ve uygulamalar yapan bir disiplindir (Seligman, Steen, Park ve Peterson, 2005). Pozitif psikoloji yaklaşımı, Seligman ve meslektaşları tarafından davranış bozukluklarına dayalı yaklaşımları tamamlamak üzere hümanistik psikoloji kuramcılarının ve araştırmacılarının eklektisizminden uyarlanarak geliştirilmiştir (Seligman, 2002; Seligman ve Csikszentmihalyi, 2000). Bireylerin güçlü yönlerini ve erdemlerini vurgulayan pozitif psikoloji yaklaşımı, bireylerin ve toplumların gelişmesine etki eden faktörlerin keşfedilmesi ve bunların teşvik edilmesi amacıyla insan işlevselliğini en üst düzeye çıkarmaktadır (Sheldon, Frederickson, Rathunde, Csikszentmihalyi ve Haidt, 2000). Seligman ve Csikszentmihalyi (2000), psikolojik bilimin nihai hedefinin, bireylerin öznel iyi oluşlarının psikopatoloji üzerine değil, zihinsel sağlik üzerine odaklanarak değerlendirilmesini sağlamak olduğunu belirtmektedirler. Başka bir deyişle, bilim ve psikoloji uygulamasının odak noktasının, ihmal edilen misyonlarına, yani

*Bu çalışma, II. INES Uluslararası Akademik Araştırmalar Kongresinde (18-21 Ekim 2017, Antalya) sözel bildiri olarak sunulmuştur.

**Dr. Öğretim Üyesi, Alanya Alaaddin Keykubat Üniversitesi Eğitim Fakültesi, e-posta. sibel.demirtas@alanya.edu.tr

***Dr. Öğretim Üyesi, Amasya Üniversitesi Eğitim Fakültesi, e-posta. kemalbaytemir@gmail.com

****Dr. Öğretim Üyesi, Alanya Alaaddin Keykubat Üniversitesi Eğitim Fakültesi, e-posta. ali.gullu@ alanya.edu.tr 
normal insanları daha güçlü, üretken hale getirmek ve daha yüksek seviyede kendini gerçekleştirme ve potansiyelini ortaya koymaya yönelik farkındalık olması gerektiği vurgulanmaktadir.

"İyilik hali" (wellness) kavramı, pozitif psikolojinin temel kavramlarından birisidir. Araştırmacıların iyilik hali kavramına ve insan yaşamının tüm yönlerine olan katkısına olan ilgisi her geçen gün artmaktadır. Dünya Sağlık Örgütü'ne (WHO, 2004) göre, hem bireylerin hem de toplumların iyilik hali ve etkin işlevselliği için dayanak noktası "pozitif zihinsel sağlık" tır. Dünyayı anlamlandırmak ve karar vermek için kullandığımız bilişsel ve duyuşsal araçlarımızı kapsayan zihinsel sağlık, iyi oluşumuzu artırmamızda en anlamlı kaynaklardan birisidir (Kottke, Stiefel ve Pronk 2016). Dünya Sağlık Örgütü (WHO) tarafından da açıklandığı gibi, zihinsel sağlı yalnızca negatif belirtilerin ya da zihinsel bozuklukların olmaması ile karakterize değildir (WHO, 2004). Hem hedonik (öznel iyi olma) hem de eudaimonik (psikolojik iyi oluş) yönleri kapsayan psikolojik kaynakların varlığını da birleştiren zihinsel sağlık tanımı giderek artmaktadır (Diener, 1984; Ryan ve Deci, 2001). Öznel iyi oluş olarak da bilinen hedonik iyi oluş, keyif verici duyguların ve ruh durumlarının sık yaşandığı, negatif duyguların ve ruh durumlarının nadiren yaşandığı deneyim ve yüksek düzeyde yaşam doyumu olarak tanımlanmaktadır (Diener, 1984). İyi oluşa eudaimonik açıdan yaklaşan ve Ryff'in (1989) psikolojik iyi oluş modeli ile örneklendirilen yaklaşım, bireylerin tam olarak işlevsellik göstermek ve eşsiz yeteneklerinin farkına varmak için nasıl mücadele verdikleri üzerine odaklanmaktadır. Mental iyi oluş, insanların yaşam içerisinde karşılaştıkları stres faktörleri ile baş edebilecekleri ve yaşadıkları topluma katkı sağlayabilecekleri duygusal, psikolojik ve sosyal iyi oluş durumlarını ifade etmektedir (Ryan ve Deci, 2001). Warwick-Edinburgh Mental İyi Oluş Ölçeği (WEMIOÖ), Tennant ve diğerleri (2007) tarafından İngiltere'de yaşayan bireylerin mental iyi oluş düzeylerini ölçme amaciyla geliştirilmiştir. İyi oluşun hem hedonik (örnek, öznel iyi oluş, pozitif duyguların sıklığı, yüksek yaşam doyumu ve olumsuz duyguların azlığı) hem de eudaimonik (yani psikolojik işlevsellik, kendini gerçekleştirme) boyutlarını kapsayan ölçek pozitif maddelerden oluşmaktadır.

İyi oluşla ilgili yapılan araştırmalar, iyi oluşun pek çok değişkenle ilişkili olduğunu ortaya koymaktadır. Son yıllarda araştırmacılar, öznel iyi oluş ile yaşam doyumu (Diener ve Chan, 2011), güçlü karakter özellikleri (Yasmin ve Khan, 2017), kişilik özellikleri (Doğan, 2013; Ery1lmaz ve Ercan, 2011), seyahat doyumu (Yanan, Soora, Harry ve Yuanging, 2017), öz-yeterlik (Zheng, Wang ve Xu, 2016), çevrimiçi sosyal ağların kullanımı (Fabio ve Francesco, 2017), kişilerarası yeterlik (Baytemir, 2016), yaşam amaçları ve ihtiyaç doyumu (İlhan ve Özbay, 2010), kendini açma (Şahin, 2011) arasındaki ilişkiyi ortaya çıkarmışlardır. Psikolojik iyi oluşu inceleyen araştırmalara bakıldığında psikolojik iyi oluşun, akademik başarı ve üstbiliş (İşgör, 2017), fiziksel egzersiz yapma davranışı (Gözde, 2017), yaşamda anlam (Liang, Lanxiang, Si-jie ve Wu, 2017), kişilik özellikleri (Bharti ve Bhatnagar, 2017), bireysel yenilikçilik (İkiz ve Asıc1, 2017) ve sosyal destek (Fuller-Iglesias, 2015) ile ilişkili olduğu görülmektedir. Mental iyi oluşun ise öz-anlayış (Imtiaz ve Kamal, 2016), algılanan sosyal destek (Yacoub ve Fares, 2016), bilinçli yemek yeme (Khan ve Zadeh, 2014), mizah anlayışı (Srivastava ve Maurya, 2014) gibi değişkenlerle ilişkili olduğu araştırmalarla ortaya konmuştur.

İyi oluşla yakından ilişkili diğer bir değişken umuttur. Birçok kuramcı ve araştırmacı, öznel iyi oluş ve umut arasındaki bağlantının, öznel iyi oluşun umudun bir sonucu olduğuna dair teorik mantığını ileri sürmüş ve desteklemiştir (Bailey, Eng, Frisch ve Snyder, 2007; Davis, 2005; Snyder, Lehman, Kluck ve Monsson, 2006). Umuttaki bireysel farkl1lıklar, iyi oluşun gelişiminde önemli bir faktör olarak görünmektedir (Ciarrochi, Heaven ve Davies, 2007). Umut, insan yaşamının kaynağı olarak (Kylma, 2005) görülmesinin yanı sıra iyi oluşa katkıda bulunan bir iyileştirme kuvveti (Holdcraft ve Williamson, 1991) olarak düşünülmektedir. Geleneksel teoriler, umudu; hedefe ulaşmayı, yaşam olaylarını, yaşam koşullarını ve karakter gücünü destekleyen iyimser bir duygu olarak kavramsallaştırmaktadır (Menninger, 1959; Peterson ve Seligman, 2004; Stotland, 1969). Daha sonra bilişsel davranışçı ve klinik uygulamalar bağlamında geliştirilen umuda ilişkin bilişsel kuram, umudu; alternatif yollar düşüncesi ve eyleyici düşünme olmak üzere birbirleriyle ilişkili ancak ayrı bilişsel bileşenler olarak 
tanımlamaktadır (Snyder, Lapointe, Crownson ve Early, 1998). Alternatif yollar düşüncesi (pathways), hedeflerin etkin bir şekilde geliştirilmesini temsil eder ve "Bunu yapmanın bir yolunu bulacağım" gibi ifadelerle temsil edilmektedir (Snyder, Rand ve Sigman, 2005). Eyleyici düşünce (agency) ise bunu yapmak için yönlendirilen hedef ve motive edici dürtüdür (Cotton Bronk, Holmes ve Talib, 2010). Snyder ve meslektaşlarına göre; umuda ilişkin temel unsur, birey için ulaşılabilir olarak kabul edilen hedeflere ulaşmanın olumlu beklentisidir (Snyder, Lehman, Kluck ve Monsson, 2006).

Umudun yapısı, bir bireyin hedeflerini kavramlaştırması, bu hedeflere ulaşmak için stratejiler geliştirmesi ve stratejileri kullanma motivasyonunu sürdürme becerisine yönelik algılarını yansıtır (Snyder, Lopez, Shorey, Rand ve Feldman, 2003). Araştırmalar, genel olarak yüksek umut düzeyine sahip insanların hedeflerine ulaşmada çoklu yolları daha iyi tanımlayabildiklerini, bu tür hedeflere ulaşılmasını tehdit edebilecek engellere karşı daha dirençli olduklarını, aksilikleri başarısızlıktan ziyade meydan okuma olarak gördüklerini, depresyon ve anksiyete ile etkili bir şekilde başa çıkabildiklerini ortaya koymaktadır (Arnau, Rosen, Finch, Rhudy ve Fortunato, 2007; Aspinwall ve Leaf, 2002; Snyder ve diğerleri, 1991). Synder'a $(2000 ; 2002)$ göre umut, başarı önünde engel oluşturabilecek faktörlerin yönetimini de kapsayan uzun vadeli hedeflere yönelik eylem başlatmaya ve sürdürmeye yardımcı olarak, öznel iyi oluşun artması için önemli bir yol sağlamaktadır. Psikolojik rahatsızlığı bulunan umut düzeyi yüksek bireylerin geleceğe ilişkin olumlu düşüncelere ve beklentilere sahip olması ve arzulanan sonuca ulaşabileceklerini düşünmeleri daha muhtemeldir (Snyder ve diğerleri, 1991). Diğer bir deyişle, umut, psikolojik rahatsızlığ olan bireylerin pozitif duyguları artırmalarına ve yapıcı davranışları sürdürmelerine yardımcı olmaktadır (Snyder ve diğerleri, 2006). Bunun yanında, genel popülasyon üzerinde yapılan bir araştırmada, umudun depresyon ile negatif bir ilişki ve yaşam doyumu ile pozitif bir ilişki içinde olduğu bulunmuştur (Chang, 2003). Ayrıca umudun, özyeterlik (Tarhan, 2012), psikolojik iyi oluş (Sarı ve Tunç, 2016; Shorey, Little, Snyder, Kluck ve Robitschek, 2007) ve yüksek yaşam doyumu ile (Bailey, Eng, Frish ve Synder, 2007; Wong ve Lim, 2009) pozitif yönde güçlü ilişkilere sahip olduğu bulunmuştur.

$\mathrm{Bu}$ araştırma, Snyder'in umudun, karşı1ıklı olarak sağlanan hedef yönelimli kararlılık ve hedefe ulaşma yollarının planlanması üzerine kurulu bilişsel görüşe dayanmaktadır (Snyder ve diğerleri, 1991). Bir kişinin hedefe ulaşmaya ilişkin düşünme biçimi, sonuçlar üzerinde etkili olabilmektedir. Şöyle ki; umut düzeyi yüksek bireyler, olumlu duygular yaşamakta ve başarı önündeki engelleri stres yaratan faktörler olarak değil, aşılması gereken güçlükler olarak görme eğilimi göstermektedirler (Oettingen ve Gollwitzer, 2002). Bu bağlamda, araştırmada aracılık rolü incelenen yapılandırmacı düşünmenin umutla ilişkili bir değişken olduğunu söyleyebiliriz. Yapılandırmacı düşünme, bir kişinin gerçek yaşam sorunlarını çözme biçimini etkileyen bir dizi yapıcı ve yıkıcı otomatik düşünce ile ilişkilidir (Epstein, 1992; Epstein ve Meier, 1989; Katz ve Epstein, 1991). Bilişsel-Yaşantısal Teori'ye göre "yapılandırmacı düşünme” günlük yaşamdaki uyumlu ve uyumsuz davranışı anlamak için merkezi öneme sahip bir kavramdır. Yapılandırmacı düşünme kavramı, pratik zekâ modeli (Sternberg ve Wagner, 1986) ile akılcı olmayan düşünme modelini (Ellis, 1962) bütünleştirir. Pratik zekâ kavramında olduğu gibi yapılandırmacı düşünme "neden zeki insanların gerçek yaşamda başarılı olamadıkları" sorusunu ele almak için ortaya çıkmıştır (Epstein ve Meier, 1989). Ellis'in akılcı olmayan inanç kavramına gönderme yapan Epstein, insanların duyguları ile başaçıkma yollarının onların entelektüel yeteneklerini nasıl etkili bir şekilde kullandıklarına karar vermede önemli bir etken olduğunu belirtir (Epstein, 1992; Epstein ve Meier, 1989; Katz ve Epstein, 1991). Yapılandırmacı düşünme düzeyi yüksek bireyler, duygularını kontrol etmede onlara yardımcı olan ya da başa çıkmada eylem yönelimli yaklaşım sergilemelerini sağlayan uyumlu düşüncelere sahiptir. Buna karşın, düşük yapılandırmacı düşünme düzeyine sahip bireyler, duygu izleme sürecine karışan uyumsuz otomatik düşünceleri devam ettirirler. Bunun sonucu olarak, kendilerine ve başkalarına yönelik aşırı genellemeler aracılığıyla etkili olmayan başa çıkma süreçleri kullanırlar (Epstein ve Meier, 1989). Epstein'a (2001) göre yapılandırmacı düşünen bireyler, olumsuz olayların ardından genelleme yapmazlar ve etkili eyleme yönelik yollarla düşünürler. Yapılandırmacı düşünme eğitiminin, insanların günlük yaşamlarındaki duygu, düşünce ve davranışlarını geliştirmede 
yararlı bir prosedür olduğu araştırmalarca ortaya konmuştur (Epstein, 1998, 2001). Yapılandırmacı düşünme eğitimi, insanlara farkındalık kazandırarak, uygun bir biçimde uyumsuz örtük inançlarını ve bilgi işletim biçimini değiştirerek yaşam kalitelerini geliştirmeyi amaçlar (Epstein, 1998). Ülkemizde, Demirtaş (2016) tarafindan üniversite öğrencilerinin yapılandırmacı düşünme düzeylerini artırmayı hedefleyen deneysel bir çalı̧̧ma kapsamında geliştirilen psiko-eğitim programının etkili olduğu sonucuna varılmıştır. Yapılandırmacı düşünme, mesleki performans, mesleki başarı, başarılı romantik, kişisel ve sosyal ilişkiler, akademik başarı, iyi oluş gibi pek çok olumlu özellikle ilişkilidir (Epstein, 1998). Ayrıca yurt dışında ve yurt içinde yapılandırmacı düşünmeyle ilgili yapılan araştırma bulguları bağlamında, yapılandırmacı düşünmenin; stresle başa çıkma (Katz ve Epstein, 1989; Scheuer ve Epstein, 1997; Karadağ, Baloğlu ve Yüksel, 2009), depresyon (Pacini, Muir ve Epstein, 1998), evlilik doyumu (Freeman, 1998), öznel iyi oluş (Harris ve Lightsey, 2005), bağlanma stilleri (Lopez, 1996), kişilerarası uyum ( Park, Moore, Turner ve Adler, 1997), mesleki tükenmişlik (Evers, Tomic ve Brouwers, 2005), öğretmenlik yetkinliği (Korkmaz, 2010) gibi yaşamın çeşitli alanlarında oldukça etkili bir değişken olduğu söylenebilir.

$\mathrm{Bu}$ araştırma, yukarıdaki kuramsal açıklamalar ve araştırma bulguları ışığında, pedagojik formasyon eğitimi alan öğrencilerde, umut ve mental iyi oluş arasındaki ilişkide yapılandırmacı düşünmenin aracılığını incelemeyi amaçlamaktadır. Pedagojik formasyon eğitimi alan öğrencilerin, eğitim fakültelerinde öğrenim gören diğer öğretmen adayları gibi aldıkları eğitimin, kişilik özelliklerinin, güçlü yönlerinin ve geliştirilmesi gereken diğer yönlerinin gelecek nesiller üzerinde etkili olabileceği düşünülmektedir. Umudun iyi oluş üzerindeki rolü literatürde çeşitli araştırmalarda gösterilmiş olmasına rağmen, umut ve iyi oluş arasındaki ilişkide yapılandırmacı düşünmenin rolü bugüne kadar hiçbir çalışmada ele alınmamıştır. Bu bakımdan bu araştırmanın hem yurtiçi hem de yurtdışı literatürde yer alan boşluğu dolduracağ düşünülmektedir.

\section{Yöntem}

\section{Araştırma modeli}

$\mathrm{Bu}$ çalışmada ilişkisel desen kullanılmıştır. Araştırmada, umut (yordayıcı değişken), yapılandırmacı düşünme (aracı değişken) ve mental iyi oluş (sonuç değiş̧eni) değişkenleri arasındaki nedensel ilişkiler aracılık analizleri yapılarak değerlendirilmiştir.

\section{Çalışma grubu}

Araştırmanın çalışma grubu, 2017 yılında yaz döneminde Alanya Alaaddin Keykubat Üniversitesi'nde pedagojik formasyon eğitimine devam eden, 212'si kadın (\%74.4), 73'ü erkek (\%25.6) toplam 285 kişiden oluşmaktadır. Araştırmaya katılanların yaş ortalaması 20.49, $\mathrm{Ss}=2.09$ 'dur. Araştırma grubunun belirlenmesinde uygun örnekleme yöntemi kullanılmıştır. Uygun örnekleme yöntemi, araştırmacının en ulaşılabilir örneklem üzerinde çalışmasıdır (Cohen, Manion ve Morrison, 2007).

\section{Veri toplama araçları}

Sürekli Umut Ölçeği (SUÖ): Snyder ve diğerleri (1991) tarafindan geliştirilen SUÖ, on beş yaş ve üstündeki bireylerin sürekli umut düzeylerini belirlemeyi amaçlamaktadır. Ölçek, "alternatif yollar düşüncesi" ve "eyleyici düşünce" olmak üzere iki boyut olup toplam 12 maddeden oluşmaktadır. Alt boyutlarda dörder madde yer almakta ve bu maddelerden bir tanesi geçmişe, iki tanesi içinde bulunulan zaman ve bir tanesi de geleceğe ilişkin ifadeleri içermektedir. Geriye kalan dört madde umutla ilişkili olmayan dolgu maddelerdir. Ölçek, sekizli derecelendirmeli likert tipi bir ölçme aracıdır. Alt boyutlardan elde edilen puanların toplamı sonucunda Sürekli Umut Ölçeği toplam puanı hesaplanmaktadır. Ölçeğin Türk Kültürü'ne uyarlanması Tarhan ve Bacanlı (2015) tarafından gerçekleştirilmiştir. Yapı geçerliği çalışmalarında açımlayıcı faktör analizi (AFA) sonucunda ölçeğin iki faktörde toplandığı ve toplam varyansın \% 61'ini açıkladığ bulunmuştur. Doğrulayıcı faktör analizi (DFA) sonucu uyum indeksi değerlerinin GFI = .96, 
AGFI $=.92$, RMR $=.08$, NNFI $=.94$, RFI $=.90$, CFI $=.96$ ve RMSEA $=.077$ olduğu görülmüştür. Ölçeğin iç tutarlılık katsayısı 0.84 olarak bulunurken test tekrar test güvenirlik katsayısının ise Eyleyici Düşünce alt boyutu için 0.81, Alternatif Yollar Düşüncesi boyutu için 0.78 ve ölçeğin tamamı için 0.86 olarak hesaplanmıştır. Analiz sonuçlarına göre SUÖ'nün Türkçe formunun üniversite öğrencilerinin umut düzeylerinin ölçümünde kullanılabilir bir araç olduğu sonucuna varılmıştır. Ayrıca bu araştırmada ölçeğin tamamı için iç tutarlılık katsayısı .89 olarak bulunmuştur.

Warwick Edinburgh Mental L̇yi Oluş Ölçeği (WEMIOÖ): Tennant ve diğerleri (2007) tarafından İngiltere'deki bireylerin iyi oluş düzeylerini ölçmek amacıyla geliştirilmiştir. "Psikolojik iyi oluş" ile "öznel iyi oluşu” kapsayan ölçek toplam 14 maddeden oluşmakta ve mental iyi oluşu ölçmeyi amaçlamaktadır. Ölçekten alınan yüksek puanlar yüksek mental iyi oluşun göstergesidir. Ölçeğin Türk Kültürü'ne uyarlanması Keldal (2015) tarafından gerçekleștirilmiștir. Yapı geçerliği için yapılan AFA sonucunda, ölçek maddelerinin orijinal halinde olduğu gibi tek boyutta toplandığı ve toplam varyansın \%51'ini açıkladığı ortaya çıkmıştır. DFA sonucu uyum indeksi değerleri $\mathrm{X}^{2} / \mathrm{sd}=3.71, \mathrm{RMR}=.05, \mathrm{NNFI}=.95, \mathrm{RFI}=$ $.93, \mathrm{CFI}=.96$ olarak bulunmuştur. Ölçeğin Cronbach Alfa iç tutarlık güvenirlik katsayısı 0.92 olarak hesaplanmıştır. Madde analizi sonucunda ise, ölçek maddelerinin faktör yük değerlerinin .55 ile .82 arasında değiştiği ortaya çıkmıştır. Analiz sonuçlarına göre, ölçeğin mental iyi oluşu değerlendirmede geçerli ve güvenilir bir ölçme aracı olduğunu sonucuna varılmıştır (Keldal, 2015). Ölçeğin bu araştırma için hesaplanan iç tutarlılık katsayıs1 .89'dur.

Yapılandırmacı Düşünme Envanteri: Yaşantısal sistemin zekâsına dayalı olarak kişilerin yapılandırmacı ve yapılandırmacı olmayan (yıkıcı) başaçıkma becerilerini ölçmeyi hedefleyen Yapılandırmacı Düşünme Envanteri (Constructive Thinking Inventory), Epstein ve Meier (1989) tarafından geliştirilmiştir. Yapılandırmacı Düşünme Envanteri’nin, Türk Kültürü’ne uyarlama çalışması, Tosun ve Karadağ (2008) tarafından yapılmıştır. 362 öğretmen üzerinde yürüttükleri yapı geçerliliği çalışmalarında açımlayıcı faktör analizi kullanılmış, faktör yükleri .30’un altındaki maddeler çıkartıldığında 85 maddelik bir ölçek ortaya çıkmıştır. Faktör analizi sonucunda Yapılandırmacı Düşünme Envanteri'nin Türkçe formu 7 alt ölçek ve 14 alt faktörden oluştuğu ve açıkladığ 1 toplam varyans miktarının \%47 olduğu görülmüştür. Envanterin faktörleri için hesaplanan iç tutarlılık katsayısı .52 ile .75 arasında değişmekle beraber ölçeğin geneli için Cronbach Alpha iç tutarlı1ık katsayısı .78 olarak saptanmıştır (Tosun ve Karadağ, 2008). Demirtaş (2016), ölçeğin doğrulayıcı faktör analizi ve güvenirlik analizlerini 459 üniversite öğrencisi üzerinde yinelemiştir. Bulgular, ölçeğin bireylerin yapılandırmacı düşünme düzeylerini değerlendirmede geçerli ve güvenilir bir ölçme aracı olduğunu ortaya koymaktadır. Ayrıca bu araştırmada ölçeğin tamamı için hesaplanan iç tutarlılık katsayısı .87'dir.

Kişisel Bilgi Formu: Katılımcıların, cinsiyet, yaş ve sınıf düzeylerini belirlemek amacıyla araştırmacılar tarafindan oluşturulmuş̧ur.

\section{İşlem}

Kişisel bilgi formu ve veri toplama araçları, araştırmaya gönüllü olarak katılan öğrencilere uygulanmıştır. Uygulama yaklaşı olarak 30-35 dakika sürmüştür. Verilerin analizinde betimsel istatistikler, Pearson korelasyon katsayısı kullanılmıştır. Verilerin "doğrusallık" ve "normallik" sayıltılarına zarar verecek uç değerler olup olmadığını anlamak amacıyla Mahalanobis uzaklık değerleri hesaplanmıştır. Mahalonobis uzaklık değeri $\chi^{2}(3 ; 01)=11.35$ 'den büyük 1 gözlem (multivariate outlier) değerlendirme dışında bırakılmıştır. Analizlere 284 gözlem üzerinden devam edilmiştir. Verilerin normal dağılıma sahip olup olmadığını belirlemek için basıklık ve çarpıklık değerleri incelenmiştir. Basıklık ve çarpıklık değerleri, verilerin normal dağılıma sahip olduğunu göstermiştir (sürekli umut: çarpıklık, -.35 ve basıklık -.43; yapılandırmacı düşünme: çarpıklık, .18 ve basıklık .67; mental iyi oluş: çarpıklık, -.51 ve basıklık .17). Değişkenler arası ilişkiler incelendiğinde korelasyon değerlerinin .42 ile .61 arasında değiştiği böylece çoklu 
bağlantı problemi olmadığı görülmüştür. Araştırmada, test edilen modelin aracılık etkilerinin istatistiksel olarak anlamlılığı, Sıradan En Küçük Kareler Regresyona dayalı yaklaşım ve Bootstrap Yöntemi ile incelenmiştir (Hayes, 2012; 2013). Bootstrapping tekrar tekrar veri setlerinden örneklemler çıkarma ve yeniden örneklenen her veri setindeki dolaylı etkiyi tahmin etmeyi içeren yoğun bir hesaplama yöntemidir (Preacher ve Hayes, 2008). Araştırmanın Bootstrap analizleri, PROCESS Macro aracılığıyla "Multiple Mediation Model 4" yürütülerek gerçekleştirilmiştir. Araştırmada anlamlılık düzeyi .01 olarak alınmıştır. Verilerinin analizinde, IBM SPSS 22.0 programı kullanılmıştır.

\section{Bulgular}

Araştırmanın değişkenleri arasındaki ilişkileri belirlemek amacıyla Pearson korelasyon analizi yapılmıştır. Sürekli umut, yapılandırmacı düşünme ve mental iyi oluşa ilişkin betimsel istatistikler ve korelasyon bulguları Tablo 1'de sunulmuştur.

Tablo 1.

Araştırmanın Değişkenlerine İlişkin Betimsel İstatistikler ve Pearson Korelasyon Katsayısı Değerleri

\begin{tabular}{llllllll}
\hline Değişkenler & $\bar{X}$ & Ss & Skew. & Kurt. & 1 & 2 & 3 \\
\hline 1. Sürekli Umut & 51.29 & 7.69 & -.345 & -.429 & --- & & \\
2. Yapılandırmacı Düşünce & 278.57 & 29.47 & .176 & .672 & $.42^{* *}$ & --- & \\
3.Mental İyi Oluş & 55.95 & 8.10 & -.512 & .166 & $.61^{* *}$ & $.43^{* *}$ & --- \\
\hline
\end{tabular}

$\mathrm{N}=284, * * p<.01, * * p<.05$

Tablo 1'deki korelasyon değerleri incelendiğinde umut ile yapılandırmacı düşünmenin $(.42 \mathrm{p}<.01)$, mental iyi oluşun $(.61 \mathrm{p}<.01)$, olumlu yönde anlamlı olarak ilişkili olduğu, yapılandırmacı düşünme ile mental iyi oluşun $(.43 \mathrm{p}<.01)$, olumlu yönde anlamlı olarak ilişkili olduğu görülmüsstür. Kuramsal olarak beklendiği üzere tüm değişkenler arasında olumlu yönde anlamlı ilişkiler bulunmaktadır.

Umut ve mental iyi oluş arasında yapılandırmacı düşünmenin aracı olduğu düşünülen modele ilişkin bulgular Şekil 1'de verilmiştir.

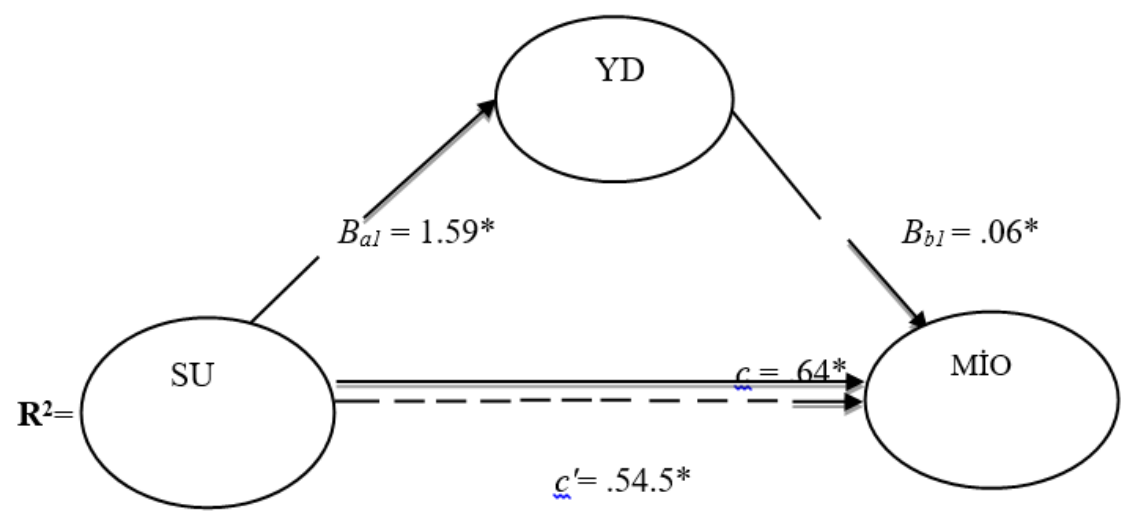

Şekil 1. Sürekli umut ile mental iyi oluş arasında yapılandırmacı düşüncenin aracıllğı ve standardize edilmemiş beta değerleri. ${ }^{*} \mathrm{p}<.01$

Şekil 1'de görüldüğ̈̈ gibi umudun, mental iyi oluş üzerindeki toplam etkisi ( $\mathrm{c}=.64$, $\mathrm{SH}=.05, \mathrm{t}=12.73, \mathrm{p}<.01)$ anlamlı düzeydedir (Adım 1). Umut düzeyinin, aracı değişken olan yapılandırmacı düşünme üzerindeki doğrudan etkisi $(\mathrm{B}=.1 .59, \mathrm{SH}=.21, \mathrm{t}=7.60, \mathrm{p}<.01)$, anlamlı düzeydedir (Adım 2). Aracı değişken olan yapılandırmacı düşünmenin, mental iyi oluş üzerindeki doğrudan etkisi $(\mathrm{B}=.06, \mathrm{SH}=.01, \mathrm{t}=4.26, \mathrm{p}<.01)$, anlamlı düzeydedir (Adım 3 ). Sürekli umut ve aracı değişken olan yapılandırmacı düşünme eş zamanlı olarak denkleme 
alındığında (Adım 4) doğrudan etki açısından umut ile mental iyi oluş arasındaki ilişki azalmış ancak anlamlılık değeri aynı düzeyde kalmaya devam etmiştir $\left(\mathrm{c}^{\prime}=-.54 .5, \mathrm{SH}=.05, \mathrm{t}=10.16\right.$, $\mathrm{p}<.01)$. Bu bulguya göre, yapılandırmacı düşünmenin, umut ile mental iyi oluş arasında kısmi aracılık yaptığı söylenebilir. Ayrıca, tüm modelin anlamlı düzeyde olduğu $(F(2-276)=95.09$, $\mathrm{p}<.01$ ) ve mental iyi oluşun toplam varyansının \% 41'ini açıkladığı görülmektedir. Araştırmada test edilen modelin değişkenleri arasındaki etkilere ilişkin değerler, Tablo 2'de sunulmuştur.

Tablo 2.

Umut, yapılandırmacı düşünme ve mental iyi oluşa ilişkin modeldeki değişkenler arasındaki ilişkiler

$\begin{array}{ll}\text { Katsayılar Çarpımı } & \text { Bootstrapping } \\ \text { (Product of coefficients) } & \% 95 \text { BCaGüven Aralığ } 1\end{array}$

\begin{tabular}{lllllll}
\hline Etkiler & Nokta tahmini & $\mathrm{SE}$ & $\mathrm{z}$ & $p$ & Düşük & Yüksek \\
\hline Dolaylı Etki & .0950 & .0248 & 3.6917 & $.01^{*}$ & .0519 & .1501 \\
Toplam Etki & .6400 & .0503 & & & .5410 & .7390 \\
Doğrudan Etki & .5450 & .0536 & & & .4394 & .6507
\end{tabular}

$\mathrm{N}=284, \mathrm{k}=5000, * p<.01, \mathrm{BCa}:$ Yanlılık hatasından arındırılmış ve düzeltilmiş (bias corrected and accelerated) 5000 bootstrap örneklemi

Araştırmada test edilen modeldeki dolaylı etkinin istatistiksel açıdan anlamlılığı, 5000 bootstrap örneklemi üzerinde incelenmiştir. Tahminler \% 95 güven aralığında değerlendirilmiş, yanlılık hatasından arındırılmış ve düzeltilmiş sonuçlar Tablo 2'de sunulmuştur. Analiz bulgularına göre, sürekli umudun, yapılandırmacı düşünme aracılığıyla mental iyi oluş üzerindeki dolaylı etkisi (yani toplam ve doğrudan etki arasındaki fark/c-c') istatistiksel açıdan önemlidir (nokta tahmin $=.0950$ ve \% 95 BCa GA [.0519,- . 1501]).

\section{Tartıșma, Sonuç ve Öneriler}

$\mathrm{Bu}$ çalışmada, umut ve mental iyi oluş arasında yapılandırmacı düşünmenin aracılığı test edilmiştir. Araştırma bulgularına göre umut ile mental iyi oluş ve yapılandırmacı düşünme arasında pozitif ilişkiler bulunmuştur. Aracılık analizinde ise umut ve mental iyi oluş arasında yapılandırmacı düşünmenin aracılığı istatistiksel açıdan önemli bulunmuştur.

Literatür incelendiğinde umut ile iyi oluş arasında anlamlı bir ilişkinin olduğu görülmektedir. Öznel iyi oluş ve umut arasındaki bağlantının, öznel iyi oluşun umudun bir sonucu olduğuna yönelik teorik model pek çok araştırmacı tarafından desteklenmiştir (Bailey ve diğerleri, 2007; Davis 2005; Garcia ve Sison, 2012; Snyder ve diğerleri, 2006; Werner, 2012). Synder'a $(2000 ; 2002)$ göre umut, başarılara müdahale edebilecek engellerin yönetimini de kapsayan uzun vadeli hedeflere yönelik eylem başlatmaya ve sürdürmeye yardımcı olarak, öznel iyi oluşun artması için önemli bir yol sağlamaktadır. Yapılan pek çok çalışmada görüldüğg̈ üzere (Amau, Rosen, Finch, Rhudy ve Fortunato, 2007; Lecci, Karoly, Briggs ve Kuhn, 1994) umut düzeyinin yüksek olması kaygı ve depresyonu azaltmakta, yaşam doyumunu, psikolojik iyi oluşu (Chang, 2003; Shorey ve diğerleri, 2007) arttırmaktadır. Dolayısıyla, bireyin mental iyi oluşu için umudun önemli bir bileşen olduğu söylenebilir. Umut seviyeleri yüksek olan bireyler, diğerleri kadar aksilik yaşasa da zorluklara uyum sağlayacak, sıkıntıyla başa çıkabilecek inançlara sahiptirler. Umutlu bireyler hedeflerinin önüne çıkan engeller karşısında negatif duygu deneyimlemek yerine alternatif yollar üreterek hedeflere ulaşma inancı taşırlar. Bu nedenle umut, iyi oluşa katkı sağlayan önemli bir kişilik özelliğidir.

İlgili alanyazına bakıldığında doğrudan, umut ile yapılandırmacı düşünme arasındaki ilişkiye yönelik bir araştırmaya rastlanmamıştır. Ancak, bu araştırma, Snyder'in umudun, karşılıklı olarak sağlanan hedef yönelimli kararlılık ve hedefe ulaşma yollarının planlanması 
üzerine kurulu bilişsel görüşe dayanmaktadır (Snyder ve diğerleri, 1991). Bu görüşle tutarlı olarak araştırmalar, umutlu bireylerin olumlu başa çıkma stratejileri kullandıklarını ortaya koymaktadır. Başa çıkma, iç ya da dış talepleri tolere etmek, stresli duyguları düzenlemek ve üzücü koşulları değiştirmek için bilişsel ve davranışsal çabalardan oluşmaktadır (Ishida ve Okada, 2006; Lazarus ve Folkman, 1984). Diğer taraftan bu araştırma bulgularının, yapılandırmacı düşünme düzeyi yüksek bireylerin özellikleri ile tutarlı olduğu görülmektedir. İyi yapılandırmacı düşünenler (good constructive thinkers) duygularını kontrol etmede onlara yardımcı olan ya da başa çıkmada eylem yönelimli yaklaşım sergilemelerini sağlayan uyumlu düşüncelere sahiptir (Epstein ve Meier, 1989). Başa çıkma tarzının seçimi esasen bir hedefe veya sonuca ulaşmak için kendi öz yeterliliğinden ve kendinden emin algılanan güven düzeyinden etkilenir (Bandura, 1989). Böylelikle, bir kişi hedef başarıya destek bulmak istediğinde başa çıkmanın uyumlu olduğu düşünülür ve bu başarıya yönelik adımlar atılır. Yukarıdaki açıklamalar ve bu araştırmanın bulgularından yola çıkarak umut ile yapılandırmacı düşünme arasında pozitif yönde bir ilişki olduğu söylenebilir.

Araştırmada ortaya çıkan diğer bulgu, yapılandırmacı düşünme ile mental iyi oluş arasında pozitif yönde anlamlı düzeyde bir ilişkinin bulunmasıdır. Bu araştırma bulgusu, Harris ve Lightsey (2005) tarafından, yapılandırmacı düşünmenin öznel iyi oluşu arttırdığını ortaya koyan araştırma bulgusu ile tutarlı görünmektedir. Yapılan araştırmalar, düşük yapılandırmacı düşünme düzeyine sahip bireylerin, yüksek yapılandırmacı düşünme düzeyine sahip olanlara göre daha fazla olumsuz duygu ve düşünce belirttiklerini (Scheuer ve Epstein ,1997), duygusal ve davranışsal başaçıkmada zorluk yaşadıklarını (Pacini, Muir ve Epstein, 1998) ortaya koymaktadır. Düşük davranışsal başaçıkma düzeyine sahip bireyler, eylemsizliği ya da etkili olmayan davranışı teşvik eden yollarla düşünürler. Onlar, eyleme geçmek yerine sorun üzerinde takılma veya erteleme eğilimi gösterirler, diğerlerinden daha az çalışırlar ya da kolaylıkla çalışmayı bırakabilirler. Diğer yandan düşük duygusal başaçıkma düzeyini teşvik eden yollarla otomatik olarak düşünen insanlar pek çok yönden uyum sorunu olan bireylerdir (Epstein, 2014). Dolayısıyla bir kimsenin yapılandırmacı düşünme düzeyinin yüksek ya da düşük olması, mental iyi oluşunu yordayan önemli bir faktördür.

Araştırmanın son bulgusu, yapılandırmacı düşünmenin umut ile mental iyi oluş arasında aracılık yaptığı, tüm modelin anlamlı düzeyde olduğu ve mental iyi oluştaki varyansın \%41'ini açıkladığını ortaya çıkarmıştır. Buna göre umut ile mental iyi oluş arasındaki ilişkide yapılandırmacı düşünmenin etkili olduğu ve mental iyi oluşu açıklamada yapılandırmacı düşünmenin önemli rolü olduğu söylenebilir. Alanyazında umut ile iyi oluş arasındaki ilişkiyi ortaya koyan pek çok çalışma olsa da umut ile iyi oluşu yapılandırmacı düşünme açısından değerlendiren bir çalışmaya rastlanmamıştır. Zihinsel sağlık, insanların yaşamdaki günlük stres faktörlerine karşı koyabileceği, yaşadıkları topluma katkıda bulunabilecekleri duygusal, psikolojik ve sosyal iyi oluş durumunu ifade etmektedir (Ryan ve Deci, 2001; Sandy ve Rioga 2013). Dünya Sağlık Örgütü, pozitif zihinsel sağlığın, hem birey hem de toplum için iyi olma ve etkili bir işleyiş için temel oluşturduğunu bildirmiştir (WHO, 2004). Araştırmalar iyi oluşun, özanlayış (Imtiaz ve Kama, 2016), öz-yeterlik (Zheng ve Wang, 2016) ve yaşamda anlam (Liang, Lan-xiang, Zhao ve $\mathrm{Wu}, 2017)$ ile pozitif yönde ilişkili olduğunu göstermektedir. Epstein ve Meier'e (2001) göre yapılandırmacı düşünme düzeyi yüksek bireyler kendilerini kabul ederler, etkili eyleme yönelik yollarla düşünürler ve gelecek için plan yaparlar. Synder umudun, bireyin başarıya giden yolda önüne çıkan engellerle başa çıkmasını da kapsayan uzun vadeli hedeflere yönelik eylem başlatmaya ve sürdürmeye yardımcı olarak, öznel iyi oluşun artması için önemli bir yol sağladığını belirtmektedir (2000; 2002). Umut düzeyi, bireyler arasında oldukça değişkenlik gösterse de, nispeten kalıcı bir özellik olarak kabul edilmektedir (Landeen ve Seeman, 2000). Umudun tanımlarının çoğunda pozitif gelecek yönelimi fikri bulunmaktadır (Landeen ve Seeman, 2000). Çeşitli yetersizlik alanlarında yapılan çalışmalar, umut yapısını, yaşam doyumu için bir yordayıcı değişken olarak kullanmıştır (Chen ve Crewe, 2009). Tüm bu araştırma bulgularından yola çıkarak, umudun bir kişilik özelliği olarak bireylerin yapılandırmacı düşünme düzeylerini etkilediği sonucuna varılabilir. Araştırmalar, umut düzeyi yüksek bireylerin, hedeflerine ulaşmada çoklu yolları daha iyi tanımlayabildiklerini, bu tür 
hedeflere ulaşılmasını tehdit edebilecek engellere karşı daha dirençli olduğunu, aksilikleri başarısızlıktan ziyade meydan okuma olarak gördüklerini, depresyon ve anksiyete ile etkili bir şekilde başa çıkabildiklerini ortaya koymaktadır (Arnau, Rosen, Finch, Rhudy ve Fortunato, 2007; Aspinwall ve Leaf, 2002; Bruininks ve Malle, 2005; Kwon, 2000; Snyder ve diğerleri, 1991). Bu bulgular yüksek yapılandırmacı düşünme düzeyine sahip bireylerin özellikleri ile uyumlu görünmektedir (Epstein, 2001; Pacini, Muir ve Epstein, 1998; Scheuer ve Epstein, 1997). Sonuç olarak, umutlu bireylerin yapılandırmacı düşünme düzeylerinin yüksek olduğu ve buna bağlı olarak da mental iyi oluş düzeylerinin pozitif yönde etkilenebileceği söylenebilir.

Araştırmanın bulguları 1şığında, ruh sağlığı alanında çalışan uzmanlara, özellikle pedagojik formasyon eğitimi alan öğrenciler gibi beliren yetişkinlik döneminde mesleki kaygılar yaşayan bireylere yönelik, umut ve yapılandırmacı düşünme düzeyini artırma çalışmalarının yapılması önerilebilir. Synder'ın umut terapisi danışanlara açık hedefler belirlemeleri, bunlara giden yollar üretmeleri, hedeflerinin peşinden gitmek üzere kendilerini motive etmeleri ve engelleri aşılması gereken meydan okumalar olarak yeniden çerçevelendirmeyi hedeflemektedir (Synder, 2000). Benzer şekilde yapılandırmacı düşünme eğitimi de, bireylerin işlevsel olmayan düşüncelerini yeniden yapılandırarak, etkili duygusal ve davranışsal başaçıkma stratejilerini kullanmalarını geliştirmeyi hedeflemektedir. Pedagojik formasyon eğitimi alan öğrencilerden düşük umut ve yapılandırmacı düşünme düzeyine sahip olanların mesleki kaygılar yaşadıkları düşünülmektedir. Bu öğrencilere yönelik psiko-eğitim ve grupla psikolojik danışma oturumları düzenlenerek, umut ve yapılandırmacı düşünme düzeylerinin artırılması, mental iyi oluşlarına önemli katkı sağlayacaktır. Ayrıca bireysel psikolojik danışma uygulamalarında, umut ve yapılandırmacı düşünme düzeyi düşük bireylere yönelik uygun psikolojik danışma planlanması önerilebilir. $\mathrm{Bu}$ çalışmada pedagojik formasyon öğrencileri üzerinde umut, yapılandırmacı düşünme ve mental iyi oluş değişkenleri ele alınmıştır. Sonraki çalışmalarda, aynı değişkenler farklı örneklemler üzerinde araştırılabileceği gibi; mental iyi oluş ile iyimserlik, bilişsel esneklik gibi değiş̧kenler arasındaki ilişkiler araştırılabilir.

Son olarak, mevcut araştırma bazı kısıtlılıklara sahiptir. Araştırma hedeflerine ulaşmış olsa da, katılımcıların uygun örnekleme yöntemi ile seçilmesi ve dolayısıyla kadın ve erkek katılımcılar arasında sayısal farklılık olması araştırmanın bir sınırlılığıdır. Araştırmanın diğer kısıtlılı̆̆ı, verilerin kesitsel niteliğidir. Modeller, değişkenler arasındaki ilişkilerin potansiyel yönlerini göstererken, nedensellik saptanamamaktadır. Gelecekteki araştırmalarda, karmaşık nedensel ilişkileri araştırmak için deneysel ve boylamsal çalışmalar yapılması önerilebilir.

\section{Kaynaklar}

Arnau, R. C., Rosen, D. H., Finch, J. F., Rhudy, J. L. ve Fortunato, V. J. (2007). Longitudinal effects of hope on depression and anxiety: A latent variable analysis. Journal of Personality, 75(1), 1-21.

Aspinwall, L. G. ve Leaf, S. L. (2002). In search of the unique aspects of hope: Pinning our hopes on positive emotions, future-oriented thinking, hard times, and other people. Psychological Inquiry, 13, 276-288.

Bailey, T. C., Eng, W., Frisch, M. B. ve Snyder, C. R. (2007) Hope and optimism as related to life satisfaction. The Journal of Positive Psychology, 2(3), 168-175. doi: 10.1080/ 17439760701409546.

Bandura, A. (1989). Regulation of cognitive processes through perceived self-efficacy. Developmental Psychology, 25, 729-735.

Baytemir, K. (2016). Ergenlikte ebeveyn ve akrana bağlanma ile öznel iyi oluş arasındaki ilişkide kişilerarası yeterliğin aracılığı. Ĕgitim ve Bilim, 41(186), 69-91.

Bharti, J. ve Bhatnagar, P. (2017). Personality and creativity as predictors of psychological wellbeing in caregivers of person with chronic mental illness. Indian Journal of Positive Psychology, 8(2), 148-153.

Bruininks, P. ve Malle, B. F. (2005). Distinguishing hope from optimism and related affective states. Motivation and Emotion, 29(4), 327-355. 
Chang, E. C. (2003). A critical appraisal and extension of hope theory in middle-aged men and women: Is it important to distinguish agency and pathways components? Journal of Social and Clinical Psychology, 22, 121-43.

Chen, R. K. ve Crewe, N. M. (2009). Life satisfaction among people with progressive disabilities. Journal of Rehabilitation, 75, 50-58.

Ciarrochi, J., Heaven, P. C. ve Davies, F. (2007). The impact of hope, self-esteem, and attributional style on adolescents' school grades and emotional well-being: A longitudinal study. Journal of Research in Personality, 41, 1161-1178. doi:10.1016/ j.jrp.2007.02.001

Cohen, L., Manion, L. ve Morrison, K. (2007). Research methods in education. London: Routledge/Falmer.

Cotton Bronk, K., Holmes, W. ve Talib, T. L. (2010). Purpose in life among high ability adolescents. High Ability Studies, 21(2), 133-145.

Davis, B. (2005). Mediators of the relationship between hope and well-being in older adults. Clinical Nursing Research, 14, 253-272. doi: 10.1177/1054773805275520.

Demirtaş, A. S. (2016). Bilişsel-Yaşantısal Teori temelli psiko-eğitim programının yapılandırmacı düşünme üzerindeki etkisi (Yayımlanmamış doktora tezi). Gazi Üniversitesi Eğitim Bilimleri Enstitüsü, Ankara.

Diener, E. (1984). Subjective well-being. Psychological Bulletin, 95(3), 542-75.

Diener, E. D. ve Chan, M. Y. (2011). Happy people live longer: Subjective well-being contributes to health and longevity. Applied Psychology: Health and Well-Being, 3(1), $1-43$.

Doğan, T. (2013). Beş faktör kişilik özellikleri ve öznel iyi oluş. Doğuş Üniversitesi Dergisi, 14(1), 56-64.

Ellis, A. (1962). Reason and emotion in psychotherapy. New York: Stuart.

Epstein, S. ve Meier, P. (1989). Constructive thinking: A broad coping variable with specific components. Journal of Personality and Social Psychology, 57(2), 332-350.

Epstein, S. (1992). Constructive thinking and mental and physical well-being. L. Montada, S. H. Filipp ve M. J. Lerner (Yay. haz.). Life crises \& experiences of loss in adulthood içinde (s. 112-125). New York: Cambridge University.

Epstein, S. (1998). Constructive thinking: the key to emotional intelligence. Westport, CT: Greenwood.

Epstein, S. (2001). Manual for The Constructive Thinking Inventory. Odessa, Florida Psychological Assessment.

Epstein, S. (2014). Cognitive-experiential theory. USA: Oxford University Press.

Eryılmaz, A. ve Ercan, L. (2011). Öznel iyi oluşun cinsiyet, yaş grupları ve kişilik özellikleriaçısından incelenmesi. Türk Psikolojik Danışma ve Rehberlik Dergisi, 4(36), 139-151.

Evers, W., Tomic, W. ve Brouwers, A. (2005). Constructive thinking and burnout among secondary school teachers. Social Psychology of Education, 8(4), 425-439.

Fabio, S. ve Francesco, S. (2017). Online networks and subjective well-being. Kyklos, 70(3), 456-480.

Fraenkel, J. R., Wallen, N. E. ve Hyun, H. H. (2012). How to design and evaluate research in education (8th ed.). New York: McGraw-Hill.

Freeman, N. (1998). Constructive thinking and early maladaptive schemas as predictors of marital satisfaction and interpersonal adjustment (Doctor of philosophy dissertation). Biola University, The Faculty of Rosemead School of Psychology.

Fuller-Iglesias, H. R. (2015). Social ties and psychological well-being in late life: the mediating role of relationship satisfaction. Aging \& Mental Health, 19(12), 1103-1112. doi: 10.1080/13607863.2014.1003285

Garcia, J. A. S. ve Sison, K. G. (2012). Locus of hope and subjective well-being. International Journal of Research Studies in Psychology, 1(3), 53-58. doi:10.5861/ijrsp.2012.297 
Gözde, E. (2017). The role of university students' general self-efficacy, depression and psychological well-being in predicting their exercise behavior. Journal of Education and Training Studies, 5(39), 110-117

Harris, P. R. ve Lightsey, O. R. (2005). Constructive thinking as a mediator of the relationship between extraversion, neuroticism, and subjective well-being. European Journal of Personality, 19, 409-426.

Holdcraft, C. ve Williamson, C. (1991). Assessment of hope in psychiatric and chemically dependent patients. Applied Nursing Research, 4, 129-134.

Horton, T. V. ve Wallander, J. L. (2001) Hope and social support factors against psychological distress of mothers who care for children with chronic physical conditions. Rehabilitation Psychology, 46(4), 399-482. doi: 10.1037/0090-5550.46.4.382

İkiz, F. E. ve Asic1, E. (2017). The relationship between individual innovativeness and psychological well-being: The example of Turkish counselor trainees. International Journal of Progressive Education, 13(1), 52-63.

İlhan, T. ve Özbay, Y. (2010). Yaşam amaçlarının ve psikolojik ihtiyaç doyumunun öznel iyi oluş üzerindeki yordayıcı rolü. Türk Psikolojik Danışma ve Rehberlik Dergisi, 4(34), 109-118.

Imtiaz, S. ve Kamal, A. (2016). Rumination, optimism, and psychological well-being among the elderly: Self-compassion as a predictor. Journal of Behavioural Sciences, 26(1), 32-50.

Ishida, R. ve Okada, M. (2006). Effects of a firm purpose in life on anxiety and sympathetic nervous activity caused by emotional stress: Assessment by psycho-physiological method. Stress Health, 22, 275-281.

İşgör, İ. Y. (2017). Üniversite öğrencilerinin psikolojik iyi oluş düzeylerinin bazı değişkenler açısından incelenmesi. Uluslararası Türkçe Edebiyat Kültür Ĕgitim Dergisi, 6(1), 494508.

Karadağ, E., Baloğlu, N. ve Yüksel, S. (2009). Yapılandırmacı düşünme ve stresle başa çıkma: Bir yapısal eşitlik modelleme çalışması. Eskişehir Osmangazi Üniversitesi Sosyal Bilimler Dergisi, 11(2), 99-122.

Katz, L. ve Epstein, S. (1991). Constructive thinking and coping with laboratory-induced stress. Journal of Personality and Social Psychology, 61, 789-800.

Keldal, G. (2015). Warwick-Edinburgh Mental İyi Oluş Ölçeği’nin Türkçe formu: geçerlik ve güvenirlik çalışması. The Journal of Happiness and Well-Being, 3(1), 103-115.

Khallad, Y. ve Jabr, F. (2016). Effects of perceived social support and family demands on college students' mental well-being: A cross-cultural investigation. International Journal of Psychology, 51(5), 348-355. doi: 10.1002/ijop.12177

Khan, Z. ve Zadeh, Z. F. (2014). Mindful eating and it's relationship with mental well-being. Social and Behavioral Sciences, 159, 69-73. doi: 10.1016/j.sbspro.2014.12.330

Korkmaz, T. (2010). İlköğretim okulu öğretmenlerinin yapılandırmacı düşünmelerinin ögretmen yetkinliğine etkisi: Bir yapısal eşitlik modelleme çalışması (Yayımlanmamış Doktora Tezi). Marmara Üniversitesi Eğitim Bilimleri Enstitüsü, İstanbul.

Kottke T. E., Stiefel, M. ve Pronk N. P. (2016). Well-being in all policies: Promoting crosssectoral collaboration to improve people's lives. Prev Chronic Dis, 13, 160155. doi: http://dx.doi.org/10.5888/pcd13.160155

Kwon, P. (2000). Hope and dysphoria: The moderating role of defense mechanisms. Journal of Personality, 68, 199-223.

Kylma, J. (2005). Dynamics of hope in adults living with HIV/AIDS: a substantive theory. Journal of Advanced Nursing, 52, 620-630.

Landeen, J. ve Seeman, V. (2000). Exploring hope in individuals with schizophrenia. The International Journal of Psychosocial Rehabilitation, 5, 45-52.

Lazarus, R. S. ve Folkman, S. (1984). Stress, appraisal, and coping. New York: Springer.

Lecci, L., Karoly, P., Briggs, C. ve Kuhn, K. (1994). Specificity and generality of motivational components in depression: A personal projects analysis. Journal of Abnormal Psychology, 103(2), 404-408. 
Liang, J., Lan-xiang, P., Si-jie, Z. ve Wu, H. (2017). Relationship among workplace spirituality, meaning in life, and psychological well-being of teachers. Universal Journal of Educational Research, 5(6), 1008-1013.

Lopez, F. G. (1996). Attachment-related predictors of constructive thinking among college students. Journal of Counseling and Development, 75(1), 58-63. doi: 10.1002/j.15566676.1996.tb02315.x

Menninger, K. (1959). The academic lecture on hope. American Journal of Psychiatry, 116, 481-194.

Pacini, R., Muir, F. ve Epstein, S. (1998). Depressive realism from the perspective of cognitiveexperiential self theory. Journal of Personality and Social Psychology, 74(4), 10561068.

Park, C. L., Moore, P. J., Turner, R. A. ve Adler, N. E. (1997). The roles of constructive thinking and optimism in psychological and behavioral adjustment during pregnancy. Journal of Personality and Social Psychology, 73, 584-592.

Peterson, C. ve Seligman, M. E. P. (2004). Character strengths and virtues. New York, NY: Oxford University Press.

Preacher, K. J. ve Hayes, A. F. (2008). Asymptotic and resampling strategies for assessing and comparing indirect effects in multiple mediator models. Behavior Research Methods, 40, 879-891.

Oettingen G. ve Gollwitzer P. M. (2002) Turning hope thoughts into goal-directed behavior. Psychological Inquiry, 13, 304-7.

Ryan, R. M. ve Deci, E. L. (2001). On happiness and human potentials: A review of research on hedonic and eudaimonic well-being. Annual Review of Psychology, 52(1), 141-66.

Ryff, C.D. (1989). Happiness is everything, or is it? Explorations on the meaning of psychological well-being. Journal of Personality and Social Psychology, 57, 10691081.

Sandy, P. T. ve Rioga, M. (2013). Caring for the person with mental health needs in the community. Sines et al (Yay. haz.). Community and public health nursing içinde (s.119). UK: Wiley Blackwell.

Şahin, G. N. (2011). Üniversite ögrencilerinin kendini açma, öznel iyi oluş ve algıladıkları sosyal destek düzeylerinin karşılaş̧tırılması (Yayımlanmamış yüksek lisans tezi). Dokuz Eylül Üniversitesi Eğitim Bilimleri Enstitüsü, İzmir.

Sarı, T. ve Tunç, E. (2016). Üniversite öğremcilerinde umudun yordayıcısı olarak psikolojik iyi olma. International Journal of Social Science, 45, 291-302.

Scheur, E. ve Epstein, S. (1997). Constructive thinking, reactions to a laboratory stressors, and symptoms in everday life. Anxiety, Stress, and Coping, 10, 269-303.

Seligman, M. E. (2002). Authentic happiness: Using the new positive psychology' to realize your potential for lasting fulfillment. New York: Free Press.

Seligman, M. E. ve Csikszentmihalyi, M. (2000). Positive psychology: An introduction. American Psychologist, 55(1), 5-14. doi: 10.1037/0003-066X.55.1.5

Seligman, M. E., Rashid, T. ve Parks, A. C. (2006). Positive psychotherapy. American Psychologist, 6(8), 774-788. doi: 10.1037/ 0003-066X.61.8.774

Seligman, M. E., Steen, T. A., Park, N. ve Peterson, C. (2005). Positive psychology progress: Empirical validation of interventions. American Psychologist, 60(5), 410-421. doi: 10.1037/0003-066X.60.5.410

Sheldon, K. M, Fredrickson, B., Rathunde, K., Csikszentmihalyi, M. ve Haidt, J. (2000). Positive psychology manifesto. Erişim adresi: www.positivepsvchology.org /akumalmanifesto.htm.

Shorey, H. S., Little, T. D., Snyder, C. R., Kluck B. ve Robitschek, C. (2007). Hope and personal growth initiative: a comparison of positive, future-oriented constructs. Personality and Individual Differences, 43, 1917-26.

Snyder, C. R. (2000). Hypothesis: There is hope. C. R. Snyder (Yay. haz.). Handbook of hope: Theory, measures and applications içinde (s. 3-21). San Diego, Calif.: Academic Press. 
Snyder, C. R. (2002). Hope theory: Rainbows in the mind. Psychological Inquiry, 73(4), 249275. doi: 10.1207/S15327965PLI1304 01

Snyder, C. R., Harris, C., Anderson, J. R., Holleran, S. A., Irving, L. M., Sigmon, S. T., Yoshinobu, L., Gibb, J., Langelle, C. ve Harney, P. (1991). The will and ways: Development and validation of an individual-differences measure of hope. Journal of Personality and Social Psychology, 60, 570-585.

Snyder, C. R., Lapointe, A. B., Crowson, J. J. ve Early, S. (1998). Preferences of high and low hope people for self-referential input. Cognition and Emotion, 12, 807-823.

Snyder, C. R., Lehman, K. A., Kluck, B. ve Monsson, Y. (2006). Hope for rehabilitation and vice versa. Rehabilitation Psychology, 51 (2), 89-112. doi: 10.1037/0090-5550.51.2.89.

Snyder, C. R., Lopez, S. J., Shorey, H. S., Rand, K. L. ve Feldman, D. B. (2003). Hope theory, measurements, and applications to school psychology. Psychology Quarterly, 18, 122139.

Snyder, C. R., Rand, K. ve Sigman, D. R. (2005). Hope theory: A member of the positive psychology family. C. R. Snyder ve S. L. Lopez (Yay. haz.). Handbook of positive psychology içinde (s. 257-276). New York: Oxford University Press.

Srivastava, U. R. ve Maurya, V. (2014). Sense of humor and psychological health among health care professionals. Indian Journal of Positive Psychology, 5(4), 376-381.

Sternberg, R. J. ve Wagner, R. K. (Ed.). (1986). Practical intelligence: nature and origins of competence in the everyday world. England: Cambridge University.

Stotland, E. (1969). The psychology of hope. San Francisco, CA: Jossey-Bass.

Tarhan, S. (2012). Umudun özyeterlik, algllanan sosyal destek ve kişilik özelliklerinden yordanması (Yayımlanmamış doktora tezi). Gazi Üniversitesi Eğitim Bilimleri Enstitüsü, Ankara.

Tarhan, S. ve Bacanlı, H. (2015). Sürekli umut ölçeği'nin Türkçe'ye uyarlanması: Geçerlik ve güvenirlik çalışması. The Journal of Happiness and Well-being 3(1), 1-14

Tennant, R., Hiller, L., Fishwick, R., Platt, S., Joseph, S., Weich, S., Parkinson, J., Secker, J. ve Stewart-Brown, S. (2007). The Warwick-Edinburgh mental well-being scale (WEMWBS): Development and UK validation. Health and Quality of Life Outcomes, 5(1), 50-63. doi:10.1186/1477-7525-5-63

Tosun, Ü. ve Karadağ, E. (2008). Yapılandırmacı Düşünme Envanteri'nin Türkçe'ye uyarlanması, dil geçerliği ve psikometrik incelemesi. Kuram ve Uygulamada Eğitim Bilimleri, 8(1), 225-264.

Werner, S. (2012). Subjective well-being, hope, and needs of individuals with serious mental illness. Psychiatry Research, 196(2-3), 214-219. doi: 10.1016/j.psychres.2011.10.012

Wong, S. S. ve Lim, T. (2009). Hope versus optimism in Singaporean adolescents: Contributions to depression and life satisfaction. Personality and Individual Differences, 46(5), 648-652.

World Health Organisation (2004). Promoting mental health: Concepts emerging evidence and practice. Summary report, World Health Organisation, Geneva.

Yanan, G., Soora, R., Harry, T. ve Yuanqing, W. (2017). Understanding the relationship between travel satisfaction and subjective well-being considering the role of personality traits: A structural equation model. Transportation Research Part F. Traffic Psychology and Behaviour, 49, 110-123.

Yasmin, N. ve Khan, W. (2017). Character strengths and subjective well-being: An exploratory study of Indian youth. Indian Journal of Positive Psychology, 1, 174-177. doi:10.15614/ijpp/2017/v8i2/157140.

Zheng, X., Wang, Y. ve Xu, L. (2016). Internet altruistic behavior and subjective well-being: self-efficacy as a mediator. Social Behavior and Personality, 44(9), 1575-1584.

\section{Extended Abstract}

\section{Introduction}


Positive psychology is a discipline that researches and implements the development of positive emotions and positive character traits (Seligman, Steen, Park \& Peterson, 2005). The positive psychology approach has been developed by Seligman and his colleagues, adapted from the eclecticism of humanistic psychological theorists and researchers to complement approaches based on behavioral disorders (Seligman, 2002; Seligman \& Csikszentmihalyi, 2000). The positive psychology approach, which emphasizes the strengths and virtues of individuals, maximizes human functionality for the discovery and promotion of factors affecting the development of individuals and communities (Sheldon, Frederickson, Rathunde, Csikszentmihalyi \& Haidt, 2000). The concept of "wellness" is one of the basic concepts of positive psychology. Researchers' interest in the concept of well-being and their contribution to all aspects of human life is increasing day by day. According to the World Health Organization (WHO, 2004), the basis for both well-being and effective functioning of individuals and communities is "positive mental health". Mental well-being refers to the emotional, psychological, and social well-being situations in which people can cope with the stress factors they experience in their lives and contribute to the collecting they experience (Ryan \& Deci, 2001). The Warwick-Edinburgh Mental Well-Being Scale (WEMIPC), developed by Tennant et al. (2007), was found to be associated with both hedonic (eg, subjective well-being, frequency of positive emotions, high life satisfaction and low sense of emotions) and eudaimonic performance are composed of positive items including goodness-of-fit dimensions. Many theoreticians and researchers have suggested and supported the theoretical conjecture that the link between subjective well-being and hope is a result of hope for subjective well-being (Bailey, Eng, Frisch \& Snyder, 2007; Davis, 2005; Snyder, Lehman, Kluck \& Monsson, 2006). Individual differences in hope seem to be an important factor in the development of well-being (Ciarrochi, Heaven \& Davies, 2007). Hope is considered to be a healing force (Holdcraft \& Williamson, 1991) that contributes to wellness, as well as being seen as a basic personality trait (Snyder et al., 1991) and as a source of human life (Kylma, 2005). High-hopeful individuals experience positive emotions and tend to see obstacles to success as difficulties to overcome, not as stressing factors (Oettingen \& Gollwitzer, 2002). In this context, we can say that constructive thinking which is investigated as mediating role in research is a hope-related variable. Constructive thinking is associated with a number of constructive and destructive automatic thoughts that affect the way one solves real life problems (Epstein, 1992; Epstein \& Meier, 1989; Katz \& Epstein, 1991).

In light of the above theoretical explanations and research findings, the aim of this research is to examine the mediating role of constructive thinking between hope and mental well-being in pedagogical formation students. It is thought that the education of pedagogical formation students like other teacher candidates in education faculties, personality traits, strengths and other aspects that need to be developed may be influential on future generations. Despite the fact that the role of hope on well being has been shown in various studies in the literature, the role of related constructive thinking between hope and well-being has not been addressed in any work up to now. From this point of view, it is thought that this research will fill the gap in both foreign and domestic literature.

\section{Method}

The main purpose of the present study was to investigate the mediating role of constructive thinking in the relationship between hope and mental well-being in students of pedagogy formation program in Alanya Alaaddin Keykubat University. The study group consisted of 212 female (\% 74.4) and 73 male (\%25.6). The study was conducted with 285 individuals, the mean age was 20.49 ( $\mathrm{Sd}=2.09$ ). Dispositional Hope Scale, Warwick Edinburgh Mental Well-Being Sclae and Constructive Thinking Inventory were used in data collection. Descriptive analyses and Pearson correlation coefficient were used in data analysis. The mediation effect of model tested in the research was examined for statistical significance based on Ordinary Least Squares Regression Model, and Boostrap Method. 


\section{Results and Discussion}

The total effect on mental well-being $(\mathrm{c}=.64, \mathrm{SH}=.05, \mathrm{t}=12.73, \mathrm{p}<.01)$ was significant at the level of the hope (Step 1). In addition, the direct effect of the level of hope on the constructive thinking of the mediating variable $(\mathrm{B}=.1 .59, \mathrm{SH}=.21, \mathrm{t}=7.60, \mathrm{p}<.01)$ is significant (Step 2). The direct effect on mental well-being $(\mathrm{B}=.06, \mathrm{SH}=.01, \mathrm{t}=4.26, \mathrm{p}<.01)$ was significant at the significance level (Step 3). According to this conclusion, constructive thinking can mediate between hope and mental well-being. It is also seen that the whole model is significant (F (2$276)=95.09, \mathrm{p}<.01$ ) and explains $41 \%$ of the total variance of mental well-being.

Whether the indirect effect of the model tested in the study was statistically significant was examined on the 5000 bootstrap sample. Estimates were evaluated at $95 \%$ confidence interval. The indirect effect of mental well-being (i.e, the difference between total and direct effect / c-c ') through constructive thinking has statistical significance (point estimate $=.0950$ and $95 \%$ BCA GA $[.0519,-.1501])$.

Research suggests that hopeful individuals are better on identification multiple ways of achieving their goals, are more resistant to the obstacles that may threaten to achieve such goals, that they view challenge as a challenge from failure, and that they can effectively cope with depression and anxiety (Arnau, Rosen , Finch, Rhudy \& Fortunato, 2007; Aspinwall \& Leaf, 2002; Bruininks \& Malle, 2005; Kwon, 2000; Snyder et al., 1991). These findings appear consistent with the characteristics of individuals with high constructive thinking levels (Epstein, 2001; Pacini, Muir \& Epstein, 1998; Scheuer \& Epstein, 1997). As a result, it can be said that constructive thinking levels of hopeful individuals are high and mental well-being levels can be affected positively.

Based on these results, some suggestions for further research and for experts within the field of mental health. Increasing the level of hope and constructive thinking by organizing psycho-educational and group counseling sessions for pedagogical formation students will make a significant contribution to their mental well-being. In this study, the variables of hope, constructive thinking, and mental well-being on pedagogical formation students are examined The same variables can be investigated on different samples; or the relationship between the variables such as mental well-being, optimism, and cognitive flexibility can be examined 